\title{
Psychometric Properties of Chinese Version of Work and Social Adjustment Scale for Outpatients With Common Mental Disorders: Classical Test Theory and Rasch Analysis
}

\author{
SCS Shih, ASM Chan, EYY Yeung, AMY Tsang, RLP Chiu, MHW Chu, MYC Poon
}

\begin{abstract}
Objectives: To determine the psychometric properties of the Chinese version of the work and social adjustment scale (CWSAS) in outpatients with common mental disorders, and to evaluate the correlations of CWSAS with Physical Health Questionnaire-9 (PHQ-9), General Anxiety Disorder-7 (GAD-7), World Health Organization Five Well-being Index (WHO-5), and Chinese version of the Perceived Stress Scale10 (CPSS-10).

Methods: Forward and backward translations of the CWSAS was performed. Between October 2018 and March 2020, 252 outpatients with a common mental disorder who had a job or a job plan were recruited from two psychiatric centres in Hong Kong. Participants were asked to complete the CWSAS, PHQ-9, GAD-7, WHO-5, and CPSS-10. Classical test theory and Rasch analysis were undertaken to determine the psychometric properties of the CWSAS and its correlations with other tools.

Results: Principal component analysis revealed that the CWSAS was a one-factor structure and showed adequate convergent and discriminant validities, internal consistency, item-total correlation, and interitem correlation. There was a significant group difference in terms of employment status. CPSS-10 and PHQ-9 were predictors for CWSAS score. The CWSAS was a distinct factor among other outcome measures. Rasch analysis indicated that the CWSAS was well-targeted and unidimensional. The CWSAS had an adequate person separation index, item separation index, person reliability, and item reliability. No categorical disordering was found, whereas inadequate adjacent threshold distance was reported. The item of ability to work indicated a noticeable differential item functioning in employment status and main source of finance.

Conclusion: The CWSAS is psychometrically appropriate to measure functional outcomes in outpatients with common mental disorders.
\end{abstract}

Key words: Functional status; Mood disorders; Social adjustment; Work

Sam CS Shih, Occupational Therapy Department, Kwai Chung Hospital, Hong Kong SAR, China

Ashley SM Chan, Occupational Therapy Department, Kwai Chung Hospital, Hong Kong SAR, China

Eva YY Yeung, Occupational Therapy Department, Kwai Chung Hospital, Hong Kong SAR, China

Amily MY Tsang, Occupational Therapy Department, Kwai Chung Hospital, Hong Kong SAR, China

Rose LP Chiu, Occupational Therapy Department, Kwai Chung Hospital, Hong Kong SAR, China

Menza HW Chu, Occupational Therapy Department, Kwai Chung Hospital, Hong Kong SAR, China

Magdalene YC Poon, Occupational Therapy Department, Kwai Chung Hospital, Hong Kong SAR, China

Address for correspondence: Sam CS Shih, Occupational Therapy Department, 1/F Kwai Chung Hospital Day Recovery Center, 2-10 Princess Margaret Hospital Road, Lai Chi Kok, Hong Kong SAR, China.

Email: shihcs01@ha.org.hk

Submitted: 27 October 2020; Accepted: 25 November 2021

\section{Introduction}

Common mental disorders are prevalent worldwide. In a systematic review and meta-analysis, $17.6 \%$ of respondents met the criteria for a common mental disorder during the past 12 months and $29.2 \%$ of respondents had a common mental disorder at some time during their lifetime. ${ }^{1}$ According to the Hong Kong Mental Morbidity Survey, ${ }^{2}$ the weighted prevalence estimate for any past-week common mental disorder was $13.3 \%$. The most frequent diagnosis was mixed anxiety and depressive disorder (6.9\%), followed by generalised anxiety disorder (4.2\%), depressive episode (2.9\%), and other anxiety disorders (1.5\%). Common mental disorders are often associated with functional impairment. ${ }^{3-5}$

The work and social adjustment scale (WSAS) was developed to measure the functional impairment resulting from a health problem. ${ }^{6}$ It is the most relevant and acceptable scale for people with psychosis and mood disorder, 
compared with the Social Functioning Questionnaire, World Health Organization - Disability Assessment Schedule, and Short-form 12-item Health Survey. ${ }^{7}$

The psychometric properties of WSAS have been examined in various patient groups with common mental disorders, ${ }^{8-11}$ eating disorders, ${ }^{12}$ outpatient problem gamblers, ${ }^{13}$ psychiatric outpatients with and without personality disorders, ${ }^{14}$ and bipolar mood disorders. ${ }^{15}$ WSAS has been adapted for use in child and adolescent patients with obsessive-compulsive disorder and related disorders. ${ }^{16}$ WSAS is a single-factor structure with high internal consistency (Cronbach's $\alpha, 0.73-0.96$ ) and testretest reliability $(\mathrm{r}=0.73-0.99)$. WSAS correlates with symptomatology scales such as the Physical Health Questionnaire-9 (PHQ-9), General Anxiety Disorder-7 (GAD-7), and Hospital Anxiety and Depression Scale, as well as functional scale such as Short Form-36 Health Survey. In addition, WSAS has been used in discrete types of treatment interventions for people with common mental disorders, such as cognitive behavioural therapy, ${ }^{17}$ computerised cognitive behavioural therapy, ${ }^{18}$ and bodymind-spirit groups, ${ }^{19}$ as well as for improving access to psychological therapy programme. ${ }^{11}$ Thus, WSAS is sensitive to change.

Nonetheless, there is no Chinese version of WSAS (CWSAS) available to date. The present study aimed to determine the psychometric properties of the CWSAS on outpatients with common mental disorders, and the correlations of CWSAS with PHQ-9, GAD-7, and World Health Organization - Five Well-being Index (WHO-5), and Chinese version of the Perceived Stress Scale-10 (CPSS$10)$.

\section{Methods}

This study was approved by the Kowloon West Cluster Research Ethics Committee (reference: KW/FR-18057(122-04)). Permission from authors to translate and validate WSAS was obtained. Written informed consent was obtained from each participant.

Between October 2018 and March 2020, outpatients with a common mental disorder were recruited from the West Kowloon Psychiatric Centre and East Kowloon Psychiatric Centre. Inclusion criteria were those having a job or a job plan, aged 18 to 64 years, able to communicate, read, and write in Chinese, and mentally stable (assessed by case psychiatrists). Those with psychotic symptoms/ cognitive impairment/mental retardation, ongoing medicolegal issues, organic conditions, or substance abuse were excluded.

The procedure of translation was based on the principles of good practice for the translation and cultural adaptation process for patient-reported outcomes measures. ${ }^{20}$ Two versions of CWSAS were forwardtranslated separately by a professional translator (who worked in medical translation for 8 years) and an occupational therapist (who had one year of tertiary education in Chinese and worked in mental health for 3 years). The agreement of both translated versions with the original version was reviewed by an expert panel of four occupational therapists (who had $>10$ years of mental health practice) using a four-point Likert scale (totally disagree, disagree, agree, and totally agree). Disagreement was reconciled through consensus. The final version received $100 \%$ of agreement among all members. Backward translation was performed separately by another professional translator and another occupational therapist who were new to the scale. Their back-translated versions were reviewed by another expert panel of five occupational therapists (who had $>10$ years of mental health practice) for any discrepancy. The two developers of WSAS were invited to comment on the backward translation. No refinement was needed. The CWSAS was field-tested in eight patients by five occupational therapists (who had at least 5 years of mental health practice). Its instructions, clarity of the items, format of the presentation, and comprehensibility were reviewed by them.

The self-reported CWSAS comprises five items: ability to work, home management, social leisure, private leisure, and close relationship. Each item is rated on a 9-point Likert scale from 0 (no impairment) to 8 (very severe impaired). Total scores range from 0 to 40 ; scores of $<10$ indicate a subclinical condition, 10 to 20 significant functional impairment but less severe clinical symptomatology, and $\geq 20$ moderately severe psychopathology.

The PHQ-9 is a nine-item self-rated questionnaire to measure the severity of depressive symptoms corresponding to the DSM-IV criteria of major depressive disorder. Each item is scored from 0 (not at all) to 3 (nearly every day). It has good reliability and validity in the Hong Kong general population..$^{21}$

The GAD-7 is a seven-item self-rated questionnaire to assess the severity of generalised anxiety disorder according to DSM-IV diagnostic criteria. ${ }^{22}$ Each item is rated from 0 (not at all) to 3 (nearly every day). It has satisfactory reliability and validity in Chinese people with epilepsy. ${ }^{23}$

The WHO-5 is a five-item self-administered scale to measure subjective psychological wellbeing. Each item is rated on a 6-point Likert scale from 0 (at no time) to 5 (all of the time). Total scores range from 0 to 25 ; higher scores indicate higher subjective wellbeing. It has satisfactory validity and reliability for people with severe mental illness in Hong Kong. ${ }^{24}$

The CPSS-10 is a ten-item self-rated scale to measure psychological stress. It consists of six positive items and four negative items. All items are scored on a 5-point Likert scale from 0 (never) to 4 (very often). Total scores range from 0 to 40 ; higher scores indicate higher perceived stress levels. It has satisfactory validity and reliability in smoking cardiac patients ${ }^{25}$ and people with common mental disorders. ${ }^{26}$

Normality of data was determined by skewness and kurtosis values between 1 and -1 and by the absolute $\mathrm{z}$ score of $<3.29 .{ }^{27}$ Construct validity of the CWSAS was evaluated 
by principal component analysis, whereas the convergent and discriminant validities of CWSAS with PHQ-9, GAD-7, WHO-5, and CPSS-10 were assessed by Pearson's correlation coefficient. Internal consistency was measured by Cronbach's alpha, item-total correlation, and inter-item correlation. Adequate internal consistency was defined as a Cronbach's alpha of $>0.7,{ }^{28}$ and item-total correlation and inter-item correlation of 0.30 to $0.90 .^{29}$ Group invariance (sex and employment status) was tested by t-test and one-way multivariate analysis of variance. Predictors of the CWSAS were determined using multiple linear regression. Level of significance was set at $\mathrm{p}<0.05$.

Goodness-of-fit for the Rasch model was evaluated using the values of mean square infit and outfit for each item. The z-standardised was excluded owing to its sample size dependency. ${ }^{30} \mathrm{~A}$ good fit was defined as 0.6 to $1.4 .^{30,31}$ The misfit pattern was reflected by the point-measure correlation, which tests whether all items are in the same direction as the construct..$^{30,32}$ The point-measure correlation of 0.40 to 0.80 was considered acceptable. ${ }^{33}$

Targeting refers to whether the item difficulty counteracts the ability of the sample. Standard error of measurement was assessed. The cut-off value for fair is 1 to 2 errors, good is $<1$ error, and very good is $<0.50$ error. $^{34}$

Local dependence assesses whether the items are highly correlated. Items that are entered in Rasch analysis should not be interdependent. ${ }^{35}$ Item pairs are considered redundant if the alpha is $>0.30$, which is determined by the paired standardised residual correlations.

Unidimensionality of the underpinning construct of the CWSAS was determined by principal component analysis of the standardised residuals. Unidimensionality is confirmed if the proportion of variance explained by the Rasch model is $>50 \%$ and the Eigenvalue of unexplained variance explained by first contrast is $<2 .^{30,31}$

Person separation index indicates whether an instrument is sensitive enough to differentiate people with a high level of perceived impairment from those with a low level of perceived impairment. Person reliability (analogue to Cronbach's alpha) refers to the reproducibility of relative measure location. A person separation index of $>2$ with person reliability of $>0.80$ indicates that the instrument can classify participants into two to three levels of performance (high, medium, and low). ${ }^{30}$

The item separation index and item reliability reflect the item hierarchy. An item separation index of $>3$ with item reliability of $>0.90$ indicates that the sample is large enough to confirm the item difficulty hierarchy of the instrument. ${ }^{30}$

Response category determines whether the rating scale is optimal. For an optimal scale, the frequencies of each category should be $>10$, the outfit mean square should be $<2.0$, and the observed average and step calibration estimates should progress monotonically across the scale. ${ }^{36}$ Otherwise, it is considered a categorical disorder. The magnitude of the distance between adjacent threshold estimates should be in the range of 1.4 to 5 .

Differential item functioning (DIF) was used to determine whether CWSAS items are invariant across subgroups of the sample. Noticeable DIF was set at the contrast $>0.50$ logits and $\mathrm{p}<0.05 .^{31}$

The classical test theory analysis was conducted using SPSS (Windows version 22; IBM Corp, Armonk [NY], US). The Rasch analysis was run with WINSTEPS (version 4.5.4).

\section{Results}

161 female and 91 male participants aged 18 to 65 (mean, $42.8 \pm 11.15$ ) years with a mean of $12.75 \pm 3.41$ years of education were recruited. The same sample had been used to assess the psychometric properties of the Chinese version of Perceived Stress Scale-10. ${ }^{26}$ The main diagnoses of participants included depression (24.6\%), adjustment disorder $(23.0 \%)$, mixed anxiety and depressive disorder $(22.2 \%)$, and generalised anxiety disorder (11.9\%) [Table 1]. The overall profile of participants was moderate depressive mood and mild anxiety. Their subjective well-being was below the cutoff value of 13 out of 25 , with significant perceived psychological stress and perceived functional impairment. Normality of data showed skewness of 0.13 and kurtosis of -0.85 , with respective absolute $\mathrm{z}$ scores of 0.75 and -2.57 .

Construct validity was assessed using exploratory factor analysis. Kaiser-Meyer-Olkin statistic was 0.83 ,

\section{Table 1. Psychiatric characteristics of participants}

\begin{tabular}{|lc|}
\hline Psychiatric characteristic & Value $^{*}$ \\
Diagnosis & \\
Depression & 24.6 \\
Adjustment disorder & 23.0 \\
Mixed Anxiety and depressive & 22.2 \\
disorder & \\
Generalised Anxiety disorder & 11.9 \\
Anxiety disorder & 6.3 \\
Panic disorder & 5.2 \\
Dysthymia & 2.4 \\
Insomnia & 1.6 \\
Specific phobia & 0.8 \\
Somatization disorder & 0.4 \\
Others & 1.6 \\
\hline Physical Health Questionnaire-9 & $10.00 \pm 6.48$ \\
\hline General Anxiety Disorder-7 & $8.84 \pm 5.70$ \\
\hline World Health Organization Five Well- & $10.33 \pm 5.82$ \\
being Index & \\
\hline Chinese version of Perceived Stress & $20.58 \pm 5.88$ \\
Scale-10 & \\
\hline Chinese version of Work and Social & $16.40 \pm 9.60$ \\
Adjustment Scale & \\
\hline
\end{tabular}

Data are presented as $\%$ or mean \pm standard deviation 
with significant Bartlett's test of sphericity (Chi square = 679.665 , degree of freedom $=10, p<0.001) .{ }^{37}$ Thus, our sample was adequate and appropriate for principal component analysis. One single factor was extracted, which accounted for $68.10 \%$ of total variance, and the Eigenvalue was 3.41. The factor loading ranged from 0.74 to 0.87 (Table 2).

The CWSAS positively moderately correlated with PHQ9 ( $\mathrm{r}=0.54, \mathrm{p}=0.01)$, GAD-7 $(\mathrm{r}=0.46, \mathrm{p}=0.01)$, and CPSS-10 ( $\mathrm{r}=0.55, \mathrm{p}=0.01)$ and negatively moderately correlated with WHO-5 $(\mathrm{r}=-0.42, \mathrm{p}=0.01)$.

Internal consistency of the CWSAS was good, with a Cronbach's alpha of 0.88 . There was no item redundancy, with the item-total correlation ranging from 0.61 to 0.78 and the inter-item correlation ranging from 0.44 to 0.71 .

Of the five items, only the ability to work item showed significant group difference (unemployment vs fulltime employment). Unemployed people had significantly higher perceived impairment in work functioning than those with full-time employment had (mean difference $=1.204$, $\mathrm{F}=4.672, \mathrm{p}<0.01)$.
The CWSAS score positively correlated with accommodation in self-owned private flat $(\mathrm{p}<0.01)$, diagnosis of depression ( $p<0.001)$, CPSS-10 ( $<<0.001)$, PHQ-9 ( $\mathrm{p}<0.001)$, GAD-7 ( $<<0.001)$, and WHO-5 $(\mathrm{p}<0.001)$. All these variables were entered in multiple linear regression analysis. Only the CPSS-10 and PHQ-9 were predicators for the CWSAS score $[F(2,249)=69.572$, $\mathrm{p}<0.001, \mathrm{R}^{2}=0.358$; adjusted $\left.\mathrm{R}^{2}=0.353\right]$. The regression equation was: CWSAS total score $=0.289+0.553 \times$ CPSS$10+0.468 \times$ PHQ-9

The Wright map showed that all items fell into the middle score zones and were within two standard deviations (Figure). Home management item was most difficult to be endorsed and social leisure was the easiest item to be endorsed. The item mean was +0.00 and the person mean was $-0.54 \pm 1.42$, which indicated higher perceived functional impairment among participants.

All items of CWSAS fit the Rasch model. The high positive point-measure correlation (range, 0.74-0.80) indicated that items aligned with the constructs, with acceptable goodness-of-fit (Table 2).

Table 2. Item hierarchy, fit statistics, separation index and reliability, factor loading, and communalities*

\begin{tabular}{|c|c|c|c|c|c|c|c|c|c|}
\hline \multicolumn{8}{|c|}{ Rasch analysis } & \multicolumn{2}{|c|}{$\begin{array}{c}\text { Exploratory } \\
\text { factor analysis }\end{array}$} \\
\hline \multirow{2}{*}{$\begin{array}{l}\text { Participants } \\
(n=252)\end{array}$} & \multirow{2}{*}{$\begin{array}{c}\text { Measure, } \\
\text { logit }\end{array}$} & \multirow{2}{*}{$\begin{array}{l}\text { Standard } \\
\text { error, } \\
\text { logit }\end{array}$} & \multicolumn{2}{|c|}{ Infit } & \multicolumn{2}{|c|}{ Outfit } & \multirow{2}{*}{$\begin{array}{c}\text { Point- } \\
\text { measure } \\
\text { correlation }\end{array}$} & \multirow{2}{*}{$\begin{array}{l}\text { Factor } \\
\text { loading }\end{array}$} & \multirow{2}{*}{$\begin{array}{c}\text { Commu- } \\
\text { nalities }\end{array}$} \\
\hline & & & $\begin{array}{c}\text { Mean } \\
\text { square }\end{array}$ & $\begin{array}{l}\text { z-stan- } \\
\text { dardised }\end{array}$ & $\begin{array}{l}\text { Mean } \\
\text { square }\end{array}$ & $\begin{array}{l}\text { z-stan- } \\
\text { dardised }\end{array}$ & & & \\
\hline Home management & 0.24 & 0.005 & 0.96 & -0.41 & 0.91 & -0.91 & 0.76 & 0.74 & 0.54 \\
\hline Personal leisure & 0.21 & 0.005 & 0.85 & -1.62 & 0.84 & -1.75 & 0.77 & 0.83 & 0.68 \\
\hline Close relationship & 0.02 & 0.005 & 1.05 & 0.53 & 0.96 & -0.35 & 0.77 & 0.87 & 0.76 \\
\hline Ability to work & -0.21 & 0.005 & 1.33 & 3.32 & 1.30 & 2.91 & 0.74 & 0.85 & 0.72 \\
\hline Social leisure & -0.25 & 0.005 & 0.88 & -1.37 & 0.84 & -1.73 & 0.80 & 0.84 & 0.70 \\
\hline
\end{tabular}

Person separation $=2.28$ or 2.20 when excluding or including extreme score; item separation (non-extreme) $=3.91 ;$ person reliability $=0.84$ or 0.83 when excluding or including extreme score; item reliability $=0.94$

Table 3. Standardised residual variance in Eigenvalue units

\begin{tabular}{|lccc|}
\hline Participants $(\mathbf{n}=\mathbf{2 5 2})$ & Eigenvalue & Observed, \% & Expected, \% \\
Total raw variance in observations & 14.42 & 100.0 & 100.0 \\
Raw variance explained by measures & 9.42 & 65.3 & 65.8 \\
Raw variance explained by persons & 4.02 & 27.9 & 28.1 \\
Raw Variance explained by items & 5.40 & 37.4 & 37.7 \\
Raw unexplained variance (total) & 5.00 & 34.7 & 34.2 \\
Unexplained variance in 1st contrast & 1.81 & 12.5 & 36.1 \\
Unexplained variance in 2nd contrast & 1.26 & 7.4 & 25.1 \\
Unexplained variance in 3rd contrast & 1.07 & 5.9 & 21.4 \\
Unexplained variance in 4th contrast & 0.86 & 0.0 & 17.1 \\
Unexplained variance in 5th contrast & 0.004 & & 0.1 \\
\hline
\end{tabular}




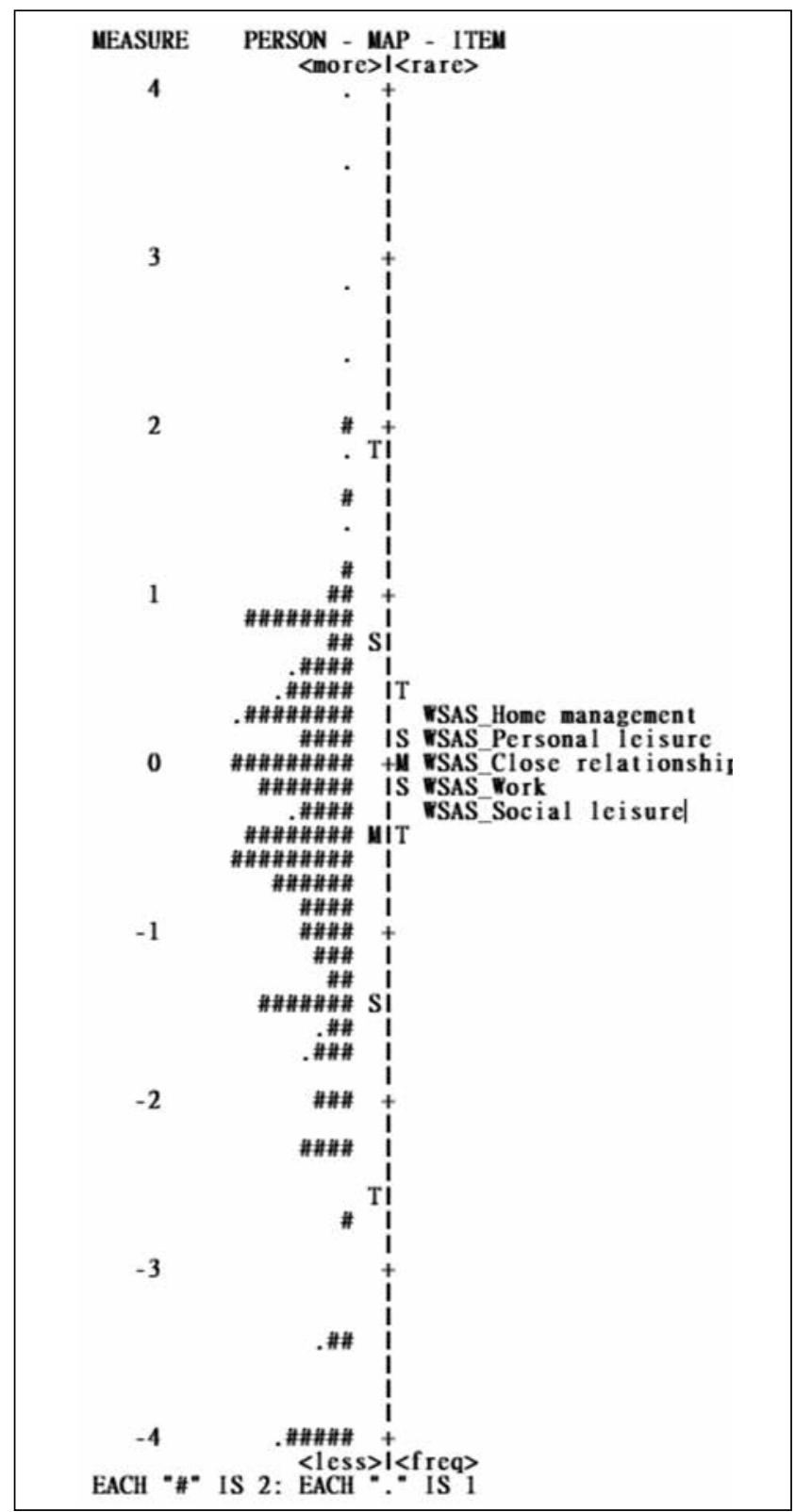

Figure. Wright map of the Chinese version of the Work and Social Adjustment Scale
Targeting was very good, as the mean standard error was 0.44 . Of 252 participants, one attained an extremely high score and $11(4.4 \%)$ attained extremely low scores. There was no significant ceiling and floor effect.

There was no local dependency, as all item pairs in the largest standardised residual correlations were negatively correlated, ranging from -0.01 to -0.47 .

The CWSAS was unidimensional, as $65.3 \%$ of the variance was explained by the Rasch model and the Eigenvalue in the first contrast of the residual variance was 1.81 (Table 3)

The person separation index was $>2$ and the person reliability was 0.84 (Table 2). The CWSAS had acceptable discriminant ability and was able to classify participants into two to three levels of impairment. The good item separation was $>3$ and item reliability was $>0.9$; the sample size was large enough to confirm the item difficulty hierarchy of the CWSAS.

Almost all criteria for optimal rating scale were achieved (Table 4). The frequencies of each category were $>10$. The values of the outfit mean square ranged from 0.72 to 1.39 . The average and step calibration progressed monotonically with categories; no categorical disordering was found. However, most of the adjacent threshold distances were not large enough to meet the minimal criteria of 1.4 logits.

None of the items displayed meaningful DIF related to age, sex, education level, marital status, current drugtaking status, child status, types of accommodation, living status, and duration of illness according to the criteria for noticeable DIF. ${ }^{31}$ However, for the item of ability to work, noticeable DIF was found in employment status (DIF contrast $=-0.61, p<0.001)$ and main source of finance (DIF contrast $=-0.63, p<0.001)$. Unemployed participants with their main source of finance other than personal income were easier to endorse than fully employed participants. They scored higher in the item of ability to work and perceived more severe impairment in work functioning.

Principal component analysis was conducted, as Kaiser-Meyer-Olkin statistic was 0.948 and Bartlett's test

Table 4. Rating scale analysis of nine-point Likert scale of the Chinese version of the Work and Social Adjustment Scale

\begin{tabular}{|lcccccc|}
\hline $\begin{array}{l}\text { Category } \\
\text { level }\end{array}$ & Count & $\begin{array}{c}\text { Observed } \\
\text { average }\end{array}$ & $\begin{array}{c}\text { Infit mean } \\
\text { square }(<\mathbf{2 . 0})\end{array}$ & $\begin{array}{c}\text { Outfit mean } \\
\text { square }(<\mathbf{2 . 0})\end{array}$ & $\begin{array}{c}\text { Step } \\
\text { calibration }\end{array}$ & $\begin{array}{c}\text { Threshold } \\
\text { distance }\end{array}$ \\
\hline 0 & 187 & -1.80 & 1.5 & 1.24 & None & - \\
\hline 1 & 162 & -1.39 & 0.86 & 0.92 & -1.78 & 1.78 \\
\hline 2 & 198 & -0.77 & 0.98 & 0.94 & -1.20 & 0.58 \\
\hline 3 & 156 & -0.44 & 0.77 & 0.72 & -0.34 & 0.86 \\
\hline 4 & 150 & -0.05 & 0.85 & 0.86 & -0.21 & 0.13 \\
\hline 5 & 129 & 0.22 & 0.83 & 0.77 & 0.20 & 0.41 \\
\hline 6 & 140 & 0.49 & 0.98 & 0.96 & 0.25 & 0.05 \\
\hline 7 & 93 & 0.90 & 0.99 & 1.00 & 1.06 & 0.81 \\
\hline 8 & 45 & 1.43 & 1.60 & 1.39 & 2.03 & 0.97 \\
\hline
\end{tabular}


Table 5. Factor loading of the Chinese version of the Work and Social Adjustment Scale (CWSAS), Physical Health Questionnaire-9 (PHQ-9), General Anxiety Disorder-7 (GAD-7), and World Health Organization Five Well-being Index (WHO-5)*

\begin{tabular}{|c|c|c|c|}
\hline \multirow[t]{2}{*}{ Item } & \multicolumn{3}{|c|}{ Factor loading } \\
\hline & Factor 1 & Factor 2 & Factor 3 \\
\hline $\begin{array}{l}\text { CWSAS_Ability to } \\
\text { work }\end{array}$ & 0.09 & 0.72 & 0.08 \\
\hline $\begin{array}{l}\text { CWSAS_Home } \\
\text { management }\end{array}$ & 0.07 & 0.82 & 0.07 \\
\hline $\begin{array}{l}\text { CWSAS_Personal } \\
\text { leisure }\end{array}$ & -0.06 & 0.88 & -0.06 \\
\hline $\begin{array}{l}\text { CWSAS_Social } \\
\text { leisure }\end{array}$ & -0.06 & 0.86 & -0.03 \\
\hline $\begin{array}{l}\text { CWSAS_Close } \\
\text { relationship }\end{array}$ & -0.02 & 0.82 & -0.06 \\
\hline PHQ-9_item 1 & 0.52 & 0.09 & -0.32 \\
\hline PHQ-9_item 2 & 0.81 & 0.05 & -0.03 \\
\hline PHQ-9_item 3 & 0.37 & 0.18 & -0.30 \\
\hline PHQ-9_item 4 & 0.53 & 0.03 & -0.35 \\
\hline PHQ-9_item 5 & 0.48 & 0.09 & -0.27 \\
\hline PHQ-9_item 6 & 0.74 & 0.08 & -0.05 \\
\hline PHQ-9_item 7 & 0.70 & 0.08 & -0.12 \\
\hline PHQ-9_item 8 & 0.68 & 0.12 & 0.01 \\
\hline PHQ-9_item 9 & 0.61 & 0.13 & 0.03 \\
\hline GAD-7_item 1 & 0.83 & -0.04 & -0.09 \\
\hline GAD-7_item 2 & 0.89 & 0.03 & 0.10 \\
\hline GAD-7_item 3 & 0.92 & -0.06 & 0.08 \\
\hline GAD-7_item 4 & 0.81 & -0.07 & -0.12 \\
\hline GAD-7_item 5 & 0.91 & -0.06 & 0.01 \\
\hline GAD-7_item 6 & 0.72 & 0.03 & -0.13 \\
\hline GAD-7_item 7 & 0.91 & -0.06 & 0.12 \\
\hline WHO-5_item 1 & 0.00 & -0.01 & 0.92 \\
\hline WHO-5_item 2 & -0.19 & 0.02 & 0.76 \\
\hline WHO-5_item 3 & 0.06 & -0.01 & 0.97 \\
\hline WHO-5_item 4 & -0.16 & 0.01 & 0.78 \\
\hline WHO-5_item 5 & 0.04 & -0.07 & 0.90 \\
\hline
\end{tabular}

Extraction method: principal component analysis; rotation method: Oblimin with Kaiser normalisation (rotation converged in five iterations) of sphericity $($ Chi square $=5755$, degree of freedom $=325$, $\mathrm{p}<0.001)$ was significant. Three factors were yielded, accounting for $68.69 \%$ of total variance. The factor loading was 0.37 to 0.92 for factor $1,0.72$ to 0.88 for factor 2, and 0.76 to 0.97 for factor 3 (Table 5). The respective Eigenvalues were $13.64,2.31$, and 1.91 and explained $52.452 \%, 8.893 \%$, and $7.349 \%$ of the variances, respectively. All items of PHQ-9 and GAD-7 were clustered into the same factor (symptomatology), whereas WHO-5 and CWSAS were extracted into the other two factors.

\section{Discussion}

Consistent with studies of psychiatric samples ${ }^{9-11,13,14}$ and the original version, ${ }^{6}$ the present study confirmed the good internal consistency and one-factor construct of the CWSAS. The CWSAS was well-targeted with no redundant items or significant ceiling or floor effect. Rasch analysis confirmed its unidimensional structure, consistent with a study of people with medical conditions ${ }^{31}$ In addition, the convergent and discriminant validities of the CWSAS was evidenced by its moderate correlation with PHQ-9 and GAD-7 as well as WHO-5 and CPSS-10 in an anticipatory direction. Multiple linear regression indicated that PHQ-9 and CPSS-10 were predictors for CWSAS score. The person separation reliability showed that the CWSAS was able to classify respondents into two to three statistically different levels of functional impairment. ${ }^{6}$

To the best of our knowledge, the response categories of this nine-point Likert scale have not been studied. It was marginally optimal because of the inadequate adjacent threshold distances, probably owing to the relatively small sample, the narrow category on latent variable, or the participants encountering difficulties discriminating between various response categories of level of impairment. ${ }^{38}$ Further studies to improve its precision should first label the scale in between two ends and verify in a larger and broader sample before collapsing the categories for analysis so as to avoid loss of information ${ }^{39}$ and to preserve its originality.

In contrast to a previous study, ${ }^{31}$ no noticeable DIF by sex was identified in any item of the CWSAS. Moreover, DIF was not significant with respect to age, year of education, duration of illness, marital status, child status, living status, types of accommodation, and current drug-taking status. However, there were significant DIF (unemployment vs employment) and group difference (unemployment vs full time employment) in employment status. This indicates that unemployed outpatients had a higher perceived functional impairment. It is understandable that the significant DIF in main source of finance (personal income vs others source of income) was discerned, as those without personal income were unemployed. It should be cautious when comparing these two groups of patients.

Treatment content focusing on the aspects of stress and depression management is crucial, as they were predictors 
of the CWSAS score. Handling interpersonal issues is indicative, as the domains related to handling interpersonal issues were easier to be endorsed in the difficulty hierarchy. Consistent with a study of people with common mental disorders, ${ }^{11}$ our study supports that the CWSAS is a distinct factor among other outcome measures and is an appropriate outcome measure for outpatients with common mental disorders.

\section{Conclusion}

The CWSAS retained its original psychometric properties and showed consistent findings in similar populations. It is a psychometrically appropriate tool to evaluate functional outcomes of outpatients with common mental disorders.

\section{Contributors}

All authors designed the study, acquired the data, analysed the data, drafted the manuscript, and critically revised the manuscript for important intellectual content. All authors had full access to the data, contributed to the study, approved the final version for publication, and take responsibility for its accuracy and integrity.

\section{Conflicts of Interest}

All authors have disclosed no conflicts of interest.

\section{Funding/Support}

This study received no specific grant from any funding agency in the public, commercial, or not-for-profit sectors.

\section{Data Availability}

All data generated or analysed during the present study are available from the corresponding author on reasonable request.

\section{Ethics Approval}

This study was approved by the Kowloon West Cluster Research Ethics Committee (reference: KW/FR-18057(122-04)). Written informed consent was obtained from each participant.

\section{Acknowledgements}

The authors thank the participants for their participation, translators for their contributions, expert panel members for their expert advice in the translation process, and the case psychiatrists for assessing the participants. Special thanks go to the developers, Dr James Mundt and Dr Isaac Marks, for granting us permission to tranlsate and validate the Work and Social Adjustment Scale and providing comments on backward translation of the Chinese version.

\section{References}

1. Steel Z, Marnane C, Iranpour C, et al. The global prevalence of common mental disorders: a systematic review and meta-analysis 1980-2013. Int J Epidemiol 2014;43:476-93. Crossref

2. Lam L, Wong C, Wang MJ, et al. Prevalence, psychosocial correlates and service utilization of depressive and anxiety disorders in Hong Kong: the Hong Kong Mental Morbidity Survey (HKMMS). Soc Psychiatry Psychiatric Epidemiol 2015;50:1379-88. Crossref

3. Aderka IM, Hofmann SG, Nickerson A, Hermesh H, GilboaSchechtman E, Marom S. Functional impairment in social anxiety disorder. J Anxiety Disord 2012;26:393-400. Crossref

4. Gili M, García Toro M, Armengol S, García-Campayo J, Castro A, Roca M. Functional impairment in patients with major depressive disorder and comorbid anxiety disorder. Can $\mathbf{J}$ of Psychiatry 2013;58:679-86. Crossref

5. Löwe B, Spitzer RL, Williams JB, Mussell M, Schellberg D, Kroenke K. Depression, anxiety and somatization in primary care: syndrome overlap and functional impairment. Gen Hosp Psychiatry 2008;30:191-9. Crossref

6. Mundt JC, Marks IM, Shear MK, Greist JH. The Work and Social Adjustment Scale: a simple measure of impairment in functioning. $\mathrm{Br}$ J Psychiatry 2002;180:461-4. Crossref

7. Crawford MJ, Robotham D, Thana L, et al. Selecting outcome measures in mental health: the views of service users. J Mental Health 2011;20:336-46. Crossref

8. Cella M, Sharpe M, Chalder T. Measuring disability in patients with chronic fatigue syndrome: reliability and validity of the Work and Social Adjustment Scale. J Psychosom Res 2011;71:124-8. Crossref

9. Jansson-Fröjmark M. The Work and Social Adjustment Scale as a Measure of Dysfunction in Chronic Insomnia: Reliability and Validity. Behav Cogn Psychother 2014;42:186-98. Crossref

10. Mataix-Cols D, Cowley AJ, Hankins M, et al. Reliability and validity of the Work and Social Adjustment Scale in phobic disorders. Compr Psychiatry 2005;46:223-8. Crossref

11. Zahra D, Qureshi A, Henley W, et al. The work and social adjustment scale: Reliability, sensitivity and value. Int J Psychiatry Clin Pract 2014;18:131-8. Crossref

12. Tchanturia $\mathrm{K}$, Hambrook D, Curtis $\mathrm{H}$, et al. Work and social adjustment in patients with anorexia nervosa. Compr Psychiatry 2013;54:4145. Crossref

13. Tolchard B. Reliability and validity of the Work and Social Adjustment Scale in treatment-seeking problem gamblers. J Addict Nurs 2016;27:229-33. Crossref

14. Pedersen G, Kvarstein EH, Wilberg T. The Work and Social Adjustment Scale: Psychometric properties and validity among males and females, and outpatients with and without personality disorders. J Psychosom Res 2011;71:124-8.

15. Echezarraga A, Calvete E, Hayas CL. Validation of the Spanish version of the Work and Social Adjustment Scale in a sample of individuals with bipolar disorder. J Psychosoc Nurs Ment Health Serv 2019;57:4451. Crossref

16. Jassi A, Lenhard F, Krebs G, et al. The Work and Social Adjustment Scale, youth and parent versions: psychometric evaluation of a brief measure of functional impairment in young people. Child Psychiatry Hum Dev 2020;51:453-60. Crossref

17. Worm-Smeitink M, Nikolaus S, Goldsmith K, Wiborg J, et al. Cognitive behaviour therapy for chronic fatigue syndrome: Differences in treatment outcome between a tertiary treatment centre in the United Kingdom and the Netherlands. J Psychosom Res 2016;87:4349. Crossref

18. Gega L, Swift L, Barton G, et al. Computerised therapy for depression with clinician vs. assistant and brief vs. extended phone support: study protocol for a randomised controlled trial. Trials 2012;13:15161. Crossref

19. Sreevani R, Reddemma K, Chan CL, Leung PP, Wong V, Chan CH. Effectiveness of integrated body-mind-spirit group intervention on the well-being of Indian patients with depression: a pilot study. J Nurs Res 
2013;21:179-86. Crossref

20. Wild D, Grove A, Martin M, et al. Principles of Good Practice for the Translation and Cultural Adaptation Process for Patient-Reported Outcomes (PRO) Measures: report of the ISPOR Task Force for Translation and Cultural Adaptation. Value Health 2005;8:94104. Crossref

21. Yu X, Tam WWS, Wong PTK, Lam TH, Stewart SM. The Patient Health Questionnaire-9 for measuring depressive symptoms among the general population in Hong Kong. Compr Psychiatry 2012;53:95102. Crossref

22. Spitzer RL, Kroenke K, Williams J, Löwe B. A brief measure for assessing Generalized Anxiety Disorder: The GAD-7. Arch Intern Med 2006;166:1092-7. Crossref

23. Tong X, An D, McGonigal A, Park S-P, Zhou D. Validation of the Generalized Anxiety Disorder-7 (GAD-7) among Chinese people with epilepsy. Epilepsy Res 2016;120:31-36. Crossref

24. Kong CL, Lee CC, Ip YC, Chow LP, Leung CH, Lam YC. Validation of the Hong Kong Cantonese Version of World Health Organization Five Well-Being Index for People with Severe Mental Illness. East Asian Arch Psychiatry 2016;26:18-21.

25. Leung DYP, Lam T-h, Chan SSC. Three versions of Perceived Stress Scale: validation in a sample of Chinese cardiac patients who smoke. BMC Public Health 2010;10:513. Crossref

26. Shih S, Chan A, Yeung E, Tsang A, Chiu R, Chu M, Poon M. Psychometric properties and correlates of Chinese version of Perceived Stress Scale (CPSS-10) in people with common mental disorders with different employment statuses. Hong Kong J Occup Ther Aug 2021. Crossref

27. Mishra P, Pandey CM, Singh U, Gupta A, Sahu C, Keshri A. Descriptive statistics and normality tests for statistical data. Ann Card Anaesth 2019;22:67-72. Crossref

28. Kline P. The handbook of psychological testing. 2nd ed. ed: Routledge;
2000.

29. Squires JE, Estabrooks CA, Newburn-Cook CV, Gierl M. Validation of the conceptual research utilization scale: an application of the standards for educational and psychological testing in healthcare. BMC Health Serv Res 2011;11:107. Crossref

30. Linacre M. Winsteps Rasch Tutorial 22012 [Available from: http:// www.winsteps.com/a/winsteps-tutorial-2.pdf.

31. Thandi G, Fear NT, Chalder T. A comparison of the Work and Social Adjustment Scale (WSAS) across different patient populations using Rasch analysis and exploratory factor analysis. J Psychosom Res 2017;92:45-48. Crossref

32. Mohaffyza M, Sulaiman N, Lai Cs, Mohd Salleh K. Measuring the validity and reliability of research instruments. Procedia Soc Behav Sci 2015;204:164-71. Crossref

33. Bond T. Applying the Rasch model: Fundamental measurement in the human sciences. New York Routledge; 2015.

34. Fisher WPJ. Rating scale instrument quality criteria. Rasch Measurement Transactions 2007;21:1095.

35. Baghaei P. Local dependency and Rasch measures. Rasch Measurement Transactions 2007;21:1105-6.

36. Linacre JM. Optimizing Rating Scale Category Effectiveness. J Appl Meas 2002;3:85-106.

37. Garson GD. Factor Analysis. NC: Statistical Associates Publishers; 2013.

38. Pallant JF, Tennant A. An introduction to the Rasch measurement model: an example using the Hospital Anxiety and Depression Scale (HADS). Br J Clin Psychol 2007;46:1-18. Crossref

39. Grondin J, Blais J-G. A Rasch analysis on collapsing categories in item's response scales of survey questionnaire: Maybe it's not one size fits all. Paper presented at: Annual Meeting of the American Educational Research Association (Denver, CO, Apr 30-May 4, 2010); 2010. 